\title{
Would online legal services guarantee the availability of justice and legal aid?
}

\author{
Anastasia Selkova* \\ Ural State Law University, Civil Procedure Department, Yekaterinburg, Russia
}

\begin{abstract}
Traditionally, legal services have been delivered in offices during face-to-face interactions between the lawyer and his client. At the present time, digital technologies have shifted that scheme as it becomes possible to communicate by telephone, with the use of the internet or in a way that involves both. The author rethinks the nature of legal services and provides a framework for understanding further developments. Special attention is focused on assumption that virtual law practice is more than just a sale of legal documents or single online task management because it provides direct and effective communication between a lawyer and a client. The article shows the difference that new technology can make for ensuring easy access to legal aid and justice. The author states that the central role in legal practices modernization belongs to lawyers who should change the way they work and have to embrace innovations. The article introduces all means for delivering legal aid that clearly have the potential to fully transform the legal services market. Also, the author outlines some dangers that may become a serious threats to the new technologies perspectives.
\end{abstract}

\section{Introduction}

Most of us at some point feel a great necessity in professional legal assistance. In the century of digitalization, it is significantly expanded by the Internet and digital technology. Undoubtedly, the appeal to a law firm or directly to the professional lawyer still remains the traditional means for the majority of the population to solve their legal issues. At the same time, both individuals and legal entities increasingly use special online services for this.

The growing popularity of legal online resources is quite comprehensible. They are an affordable alternative to services that law firms provide for citizens and business entities in the traditional format. Legal online services is a great option for those who do not need an extensive assistance of lawyers or for those who wish to cut their court costs. Most legal online services operate either on the basis of a subscription when the client pays a certain amount per month and receives a certain range of services, or on the basis of one payment for each of the appeal.

Why are legal online services such inexpensive compared to what legal firms usually charged? How does it turn out that these services are set up prices much less than lawyers? The answer is simple: these services are not law firms.

Any web site of such legal assistance service provides you with indication that this resource is not a law firm and its employees do not act as an attorney. By theirs features these online services do not replace the counselling of a lawyer and can be provided only through the Internet. Such legal assistance is actually not recognized as the legal practice.

When you get a legal service in online mode, the relationship of the type "client-attorney" does not occur. You do not hire a remote law firm that will give you legal advice. You simply use a specific online resource for your legal assistance. In other words, an appeal to online legal services can be compared with shopping at the store. But instead of choosing goods on the shelves, you will buy samples of contracts, applications or recommendations on the legal issues.

\section{Types of online legal services}

There are several Internet platforms among the key players in the online legal services market, each with its specialization. For example, there are many services for the legal documents preparation. Previously, you have to visit a lawyer in order to get proper documents. But now his role can be successfully implemented by special computer programs. These are inexpensive or even free resources, with which, any user can independently prepare a claim, draw up a contract, make other documentation and so on. Without a doubt, one of the most famous among such services is the Freshdoc online designer, with an impressive bulk base of templates and sample documents [1].

Another part of the online legal services market is occupied by services which offering consultations on typical legal issues. They are very useful because legal assistance can be obtained very quickly, in remote mode, without leaving home, through the exchange of instant 
messages or video conferencing (Internet services like Pravoved.ru [2]). Consultations can be provided as a single recommendation or as a whole series of recommendations. Similar online services are a more budget option for traditional legal advice that not everyone can afford.

Another huge development is online bots. They are special programs created to solve primitive legal tasks. For example, EGRUL_BOT summarizes information about legal entities and their founders, as well as about addresses and other contact data [3]. Through this bot, you can also get an extract from the register in PDF format.

Another service - @ktotam [4] - was created to obtain information regarding real estate objects. The user just enters the cadastral number or address and bot will inform about land category, cadastral value, number of holders, area, type of property, information about burdens.

Moreover, digital technology provides the great opportunity for law firms to cut their expenditures. In particular, they no longer have to pay for office workstations. The virtual law firm can consult most of their clients through a website through electronically performed communication. Their lawyers are able to work remotely from home by using cloud technology for files and documents distribution.

Virtual law firms have proved to be very popular in the US. American Bar Association (in abbreviated form ABA) has recognized e-lawyering as the authorized legal practice. It is also quite remarkable, that $\mathrm{ABA}$ has provided a thorough provisions and guidelines of virtual law offices structure and its law practice management. For instance, there have to be secure 'client portal' through which clients are able to communicate with the firm. It should be noted that the virtual law practice does not sell legal documents and recommendations on legal issues through its website. A virtual law practice provides direct and personal communication between a lawyer and a client rather than strictly form-generated, unbundled legal documents for sale to the public or single online task management.

It is right assumption that digital technologies will not disappear into thin air, but instead will continue their promotion on the market of professional legal services [5]. Thus, it will be possible to use technologies to grant the entire spectrum of legal services for the broader clientele.

\section{Governmental support of online legal services}

It is important to note that many innovations are entered on the initiative and with the support of state bodies. For example, in the Netherlands, the State Council on Legal Aid issues launched an online service for solving the cases of divorce and property division: the special website RechTwijzer helps citizens at all stages, from free consultation before drawing up an agreement on the property division and its transfer to the judge for final approval.
A similar service is launched in England and Wales, where citizens can submit divorce petition through the GOV.uk website. Another example of digitalization is the British C-APP website designed to assist citizens when applying for disability allowance. Practically speaking, this web site is a program with step-by-step instructions for making the appropriate application. Users are invited to answer a number of questions. During this process, you can pause at any time and return to unanswered items. In addition, your answers can be viewed and modified.

In Russia, interaction with judicial authorities also can be carried out in online mode. Since 2011, the service «My Arbitrator» has operated, for submitting applications to arbitration courts through the Internet. Since 2017, the similar system has functioned for the courts of general jurisdiction that began to accept documents in the electronic form through the special portal «Gas Pravosudie».

During the pandemic, the Russian justice system has received further development, thanks to the remote meetings and hearings that began to be carried out on Skype. Moreover, digital technologies have entered into the scope of judicial statistics, where services like Ras.arbitr.ru and CaseLook.ru are collecting data on the results of cases consideration.

Another huge part of governmental support of online legal services is presented by official websites giving basic information and advice on common problems. For example, there is an interactive website in the Netherlands providing dynamic assistance through the divorce process. The potential of such websites is significant because they also can be used as automated programs for composing documents and filing applications. To encourage such innovation, some states (the US and the Netherlands) even establish NGO or university-based organizations to accelerate further development.

Moreover, a number of governments (for example, in England and Wales) manage informational videos to assist people who are dealing with different legal issues. Telephone hotlines have been used in various ways to provide legal services for vulnerable people with no Internet. Video connection is also expanding, particularly in geographically remote areas (for instance, in Alaska and in upcountry Australia). Beside this, state support of law digitalization includes embracing of new technology by courts as a way of assisting selfrepresented parties who put considerable pressure on the judicial system. For instance, China uses Internet courts that do not require citizens to appear in court. Internet court is presented by non-human judges, powered by artificial intelligence technology. Such judges are artificial creations in the hologram form. There is no real judge. Despite this, only holographic 3D image of a judge that looks like a human and sets schedules, asks questions, takes evidence and issues documents.

Within this digital court hearing, participants are able to use video messaging to communicate with the judge, to present their evidence and objections online and resolve other procedural matters. Naturally, the Chinese Internet courts handle only a limited number of disputes: 
intellectual property cases, e-commerce matters, domain name issues, civil rights cases involving the Internet, product liability arising from online purchases. As one can see, all countries try to launch up new schemes of legal aid and take all possible advantages of its digital potential.

\section{Advantages and drawbacks of using online legal services}

As it was mentioned, online legal services are a costeffective alternative for anyone looking for minimizing their legal costs. These services are not exact replacements for usual models of legal aid, but they grant it at a much lower cost or free of charge. This is a suitable option for small businesses, individual entrepreneurs and all citizens who need legal assistance but cannot pay for it.

According to a report published by research firm IBISWorld [6], the online legal services market is growing steadily and is expected to grow by about $6 \%$ in 2021 [7]. Along with this trend, another one can be noted: an almost imperceptible increase in demand for traditional legal services, which is largely due to the availability of proper alternatives.

Online services may become the future of the legal industry. However, today they are not an ideal means of ensuring the availability of legal assistance and cannot be compared with the practical guidance and attention that you will receive at a personal appointment with a lawyer [8]. Professional law firms are also more efficient, especially if you need to take legal action or resolve a complex legal matter.

Online legal services, like other technological innovations, are unlikely to be acceptable to everyone [9]. Some users will definitely feel all the advantages of digital services due to their relative cheapness and flexibility. While others will find that the traditional model of providing legal aid is more suitable for their interests. It all depends on the budget and the needs of the individual or organization. Large corporations and enterprises still continue to work with professional law firms, but for small companies and individuals, online services will be an excellent alternative for solving simple legal issues.

Is it possible to say unequivocally that technology is not only able to increase the level of citizens' access to justice, but also to expand the scope of legal services? The positive effect of digitalization should not be overestimated [10]. There is reason for a more restrained view.

The first and, perhaps, the most obvious objection to placing excessive hope on the future perspectives of digitalization is that proper legal assistance is expressed not in the wide spread of chatbots and online consultations, but in a live conversation between a lawyer and a client, in which complex issues are discussed. These problems required an individual approach, not stereotyped solutions [11].

From this point of view, the transition of legal services into a virtual environment is only a small part of what needs to be done to ensure the rights of citizens to access to justice and legal aid. There is no doubt that the providing of online legal advice is a significant advance, but the more important issue is to fill the funding gap in the field of legal assistance so that every citizen is able to afford to hire a lawyer for representing a case before court [12].

A second noteworthy consideration relates to those citizens who are expected to gain all advantages of the new forms of legal aid but unfortunately, they are still don't have full access to them. The latest statistics indicate that only $81 \%$ of Russians have the opportunity to use the Internet every day [13]. Even if this figure will approach to $100 \%$, there would be categories of the population that do not have access to online legal services. Obviously, in the digital world, not everyone is equal. The Internet or telephone communication, to be truly effective, presupposes not only the availability of technical capabilities, but also a certain acquirement of the citizen to use new, digital means instead of more traditional ones.

As one can see, there are some dangers amid all the excitement and enthusiasm over the new technologies perspectives. The main downside here is the digital stratification, by which we mean that despite all who will be tech-beneficiaries, there still will be exclusion of some part of population from technologies [14]. There may be a lot of hurdles on this digital way - lack of physical access to the relevant technology; the poor technical ability to use it; the low cultural and psychological background to do so [15].

Another unavoidable paradox of digital legal services is a combination of universal accessibility with implicit selectivity. The internet is open to all, but there are barriers for access to it. Deficiency of operational terminal is because there are still people who do not have computer or smartphone in our digital age. Lack of the appropriate skills and experience is mostly true for some of the groups - lower-income families, elderly disabled and undereducated persons, immigrants and refugees. Cultural reluctance is reluctance in some remote rural communities to use digital services and means of communication.

As a result, we cannot yet expect digital resources to be a complete substitute for face-to-face services. Most of the people will be confused if they have to use only the phone or the internet in order to handle their legal issues. It seems that we should to supplement cold technology with human soul because some people will always need traditional face-to-face legal assistance. However, it does not mean that such kind of legal aid should continue to be the main form of legal services delivery. Indeed interactive video systems are very improved and it is possible to provide a lifelike image of a human to one who is seeking help and used to have it from the real person.

Digital era comes with the new version of legal aid, which can be described as the planned and mixed model of legal services delivery. This combination balances freely available advice on the internet, interactive video assistance for those who need it and personalized services for the most vulnerable people or the most 
complex cases. Undoubtedly, traditional practitioners should remain in the legal aid system but they do not have to be the only one help provider, unless legal assistance is needed for persons significantly affected by the access barriers mentioned earlier.

There are also another potential risks. Any computers can be hacked. If this happens, then various inconveniences and financial losses are inevitable. Other concerns arise from the question, how to guarantee access to justice for those who do not have the skills to use a computer? First of all, standard "paper" procedures can be retained for them. Second, they can be provided with assistance in submitting documents online. The latter solution seems to be more acceptable. Keeping traditional, paper-based production only for a limited category of people cannot be effective.

However, all the mentioned hazards can be compared with risk that we are willing to take, as in the case of driving a car: a traffic accident is the risk that we take when traveling by car. The advantages are significant and outweigh the perceived disadvantages. Undoubtedly, sending emails is preferable to writing paper letters and sending them by mail. Email is faster and much cheaper than letters. These benefits apply to online forms as well. Also, advice on legal issues that was received online, in some cases, is seen more preferable, since people are less prone to display embarrassment and anxiety because of their mistakes, if they are corrected by a computer.

\section{Ways of improving the legal aid system and online legal services}

A discussion about technological innovation in the field of legal services would be incomplete without proposing specific options for overcoming the hardships that exist in this area. First of all, the issue of increasing the volume of legal assistance's financing, in criminal and civil cases, should be resolved as soon as possible.

It can be truly believed that the proper administration of justice and the encouragement of civil society are the key goals of every modern state. However, the needs of justice tend to compete weakly with other objects of expenditure in the state budget (for example, healthcare, defense, education). Unfortunately, the current procedure for financing the system of free legal aid in Russia does not guarantee every citizen its gaining. In fact, the state shifted its responsibilities in terms of financing free legal aid to the constituent entities, not taking into account their differences in the level of economic development. It seems that this area should be financed from the federal budget so that everyone has equal access to free legal aid.

Second, it is vitally important to change the trend of decreasing in the number of people who have full access to qualified legal assistance. This problem is noticeably complicated by the fact that it is necessary not only to provide qualitative legal services to a significant part of the population, but also to do it at the lowest cost. In this case, financing of digital technologies that ensure the dissemination of socially significant legal services would be an acceptable option.
This will likely require the support of private sponsors who can directly invest in the development of the electronic legal services sector. An important factor is the assessment of the innovations. This will help to check their effectiveness. At the same time, it is better to entrust the expertise of innovations to an independent party, and not to a government department. In general, an autonomous institution could be created with responsibility for providing state-funded legal aid and for raising public awareness of it. Its functions may also include monitoring the quality of legal services, controlling their availability and adjusting options for the provision of legal assistance.

It is likely that in the near future it will be necessary to train court employees to work with citizens who do not have the skills to use a computer and a smartphone. Such measures are necessary to ensure that whole population can get access to justice. In general, in the future it is likely that those people who are not able to interact with technology - smartphones, computers, tablets under no circumstances will be able to initiate or participate in legal proceedings without special help.

However, once people will see the effectiveness and utility of online legal services, they will be excited to adapt to new formats. When e-mail first appeared, the idea that lawyers could use it to communicate with each other - and with clients - was considered an outrageous example of non-compliance with professional etiquette. Now it has become a routine.

\section{Conclusion}

Despite the rapidity of change in the sphere of legal assistance, we suggest that they remain low-key in their effect and some further development would be expected. It is quite clear now that the major trigger of change is the internet rather than anything else. Professional legal community have to adapt to digital technologies as the response to the emergence of new forms of legal practice. It appears that we are likely to be in the middle of a major reshaping the entire commercial marketplace of legal services. It is notably, that public funding in many countries (like the UK and the Netherlands) was also specifically forwarded to use the socially useful possibilities of digital technologies.

In our opinion, such kind of socially-oriented innovation works for the public interest and allows all interested parties to try, research and improve new technologies, thereby expanding access to justice and ensuring its fairness.

\section{References}

1. Documents design mode FreshDoc. Retrieved from: https://www.freshdoc.ru (date of access: 23.05.2021)

2. Legal advising Pravoved.ru. Retrieved from: https://pravoved.ru (date of access: 23.05.2021)

3. Internet-bot egrulbot.ru. Retrieved from: https://egrulbot.ru (date of access: 23.05.2021) 
4. Internet-bot ktotam. Retrieved from: https://ktotamik.ru (date of access: 23.05.2021)

5. V. Yarkov, Civil Process Bulletin, 1, 16 (2018)

6. Online Legal Services in the US industry outlook (2020-2025). Retrieved from: https://www. ibisworld.com/united-states/market-researchreports/online-legal-services-industry/ (date of access: 23.05.2021)

7. Eight Legal Marketing Statistics that Might Surprise You. Retrieved from: https://www.clio.com/ blog/legal-marketing-statistics/ (date of access: 23.05.202

8. E. Kanunnikova, A. Loshkarev, International Journal of Humanities and Natural Sciences, 10, 103 (2020)
9. G. Peaker, The pitfalls of free online legal advice (2012) Retrieved from: https://www.theguardian. com/law/2012/jun/12/pitfalls-online-legal-advice

10. O. Miroshnichenko, N. Safin, Modern Global Economic System: Evolutional Development, p. 928 (2021)

11. B. Hough, Harvard Journal on Law and Technology, 26, 266 (2012)

12. S. Kimbro, Harvard Journal of Law and Technology, 18, 24 (2013)

13. Digital 2020 global digital overview. Retrieved from: https://www.web-canape.ru/business/internet2020-globalnaya-statistika-i-trendy/ (date of access: 23.05.2021)

14. V. Naumov, Russian law: education, practice, science, 6, 4 (2018)

15. R. Rouvinsky, Russian Law Journal, 1, 4 (2021) 